\title{
A animação como alternativa didática
}

\author{
La animación como alternativa didáctica
}

Animation as a didactic alternative

Isabela Maria Santos Silva ${ }^{1}$

Rose Adriana Andrade de Miranda ${ }^{2}$

\begin{abstract}
Resumo
A Educação Bancária, segundo Freire, é uma educação onde os espaços escolares se apresentam estáticos, burocráticos, fixados a um ensino conteudista, de modo que o professor é o centro do processo de aprendizagem e o detentor de informação e de conhecimento. Numa realidade onde muitas escolas ainda atuam com esse viés, percebeu-se a necessidade de trabalhar com materiais didáticos originais e alternativos. Por esse motivo, o Programa de Educação Tutorial Grupo de Ação e Pesquisa em Educação Popular - PET GAPE, da Universidade Federal de Pelotas, juntamente com a EMEF Machado de Assis, que atua de forma bastante ativa e parceira da comunidade do entorno, desenvolveram uma animação com o propósito de apresentar de maneira divertida e educativa o Centro Histórico Pelotense para as pessoas. A partir da decorrente necessidade de materiais didáticos que tratassem sobre a história da formação de Pelotas, a escola Machado de Assis e o PET GAPE tiveram a ideia de criar uma animação para ajudar na fixação e difusão do aprendizado. Nesse produto audiovisual, o personagem animado vestido de docinho, característica da cidade, apresenta as imagens dos prédios históricos pelotenses, ao mesmo tempo em que conta suas histórias, memórias e acontecimentos. A pesquisa sobre os imóveis de Pelotas foi desenvolvida pelos próprios educandos do quarto e quinto ano, juntamente com o auxílio das professoras, fazendo com que esse produto fosse construído coletivamente, importante assunto a ser tratado nesse trabalho.
\end{abstract}

Palavras-Chave: animação; centro histórico pelotense; educação popular; material didático; PET GAPE.

\section{Resumen}

La Educación Bancaria, según Freire, es una educación donde los espacios escolares se presentan estáticos, burocráticos, fijados a una enseñanza conteudista, de modo que el profesor es el centro del proceso de aprendizaje y el poseedor de información y de conocimiento. En una realidad donde muchas escuelas actúan con ese sesgo, se percibió la necesidad de trabajar con materiales didácticos originales y alternativos. Por eso, el Programa de Educación Tutorial Grupo de Acción e Investigación en Educación Popular - PET GAPE, de la Universidad Federal de Pelotas, junto con la EMEF Machado de Assis, que actúa de forma bastante activa y asociada de la comunidad del entorno, hicieron una animación con el propósito de presentar de manera divertida y educativa el Centro Histórico de Pelotas para las personas. A partir de la consiguiente necesidad de materiales didácticos que tratase sobre la historia de la formación de Pelotas, la escuela Machado de Assis y el PET GAPE tuvieron la idea de crear una animación para ayudar en la fijación y difusión del aprendizaje. En ese producto audiovisual, el personaje animado vestido de dulce, característica de la ciudad, presenta las imágenes de los edificios históricos pelotenses, al mismo tiempo que cuenta sus historias, memorias y acontecimientos. La investigación sobre los inmuebles de Pelotas fue desarrollada por los propios educandos del cuarto y quinto año, junto con el auxilio de las profesoras, haciendo que ese producto fuera construido colectivamente, importante asunto a ser tratado en ese trabajo.

Palabras claves: animación; centro histórico de Pelotas; educación popular; material didáctico; PET GAPE.

\footnotetext{
${ }^{1}$ Graduanda em Cinema de Animação, Universidade Federal de Pelotas - UFPel; Pelotas, Rio Grande do Sul, Brasil; isabelamariassilva@gmail.com

${ }^{2}$ Mestre em Educação, Professora Adjunta na Faculdade de Educação na Universidade Federal de Pelotas UFPel; Pelotas, Rio Grande do Sul, Brasil; rosemiranda.educampoufpel@gmail.com
} 


\begin{abstract}
Bank Education, according to Freire, is an education where school spaces are static, bureaucratic, fixed to a content education, with the teacher is the center of the learning process and the holder of information and knowledge. In a reality where many schools still act with this bias, it was realized the need to work with original and alternative didactic materials. For this reason, the PET GAPE, of the Federal University of Pelotas, together with EMEF Machado de Assis, which acts in a very active way and a partner in the surrounding community, has developed an animation with the purpose of presenting in a fun and educational way the Historic Center of Pelotas for the people. As a result of the need for teaching materials about the history of the Pelotas formation, the Machado de Assis school and the PET GAPE had the idea of creating an animation to help in the fixation and diffusion of learning. In this audiovisual product, the animated character dressed as candy, characteristic of the city, presents the images of the historic buildings of Pelotas, while telling their stories, memories and events. The research on the properties of Pelotas was developed by the students themselves of the fourth and fifth year, together with the help of the teachers, making this product to be built collectively, an important subject to be dealt with in this work.
\end{abstract}

Keywords: animation; courseware; historic center of Pelotas; popular education; PET GAPE.

\title{
1. Introdução
}

O Grupo de Ação e Pesquisa em Educação Popular - GAPE, é um grupo de pesquisa que estuda a Educação Popular e suas formas de desenvolvimento e atuação há aproximadamente 19 anos. Com isso, em 2010, foi criado o PET GAPE, da Universidade Federal de Pelotas, que trabalha na mesma temática do grupo que o originou. O Programa de Educação Tutorial - PET, atua na perspectiva de retornar para a comunidade os investimentos na universidade pública, trabalhando através da tríade de Ensino, Pesquisa e Extensão, buscando oferecer uma graduação de excelência, formando cidadãos qualificados.

O PET GAPE é um grupo caracterizado como Conexões de Saberes, não estando vinculado a nenhum curso, tendo assim, bolsistas de várias áreas de atuação, possuindo uma temática que norteia o trabalho da equipe. Assim, o PET GAPE tem como base os princípios da Educação Popular, seguindo os pensamentos de Paulo Freire, Carlos Brandão, e muitos outros estudiosos, na qual se acredita que o processo de transformação do ensino acontece através da coletividade, de modo que escola e comunidade desempenhem seus papeis unidas. Para uma educação de qualidade, conhecimento do povo deve ser enaltecido, resultando em uma escola fortemente inserida com a cultura popular e comprometida com a mesma, pois a educação é o ponto de partida para se construir uma comunidade forte:

A educação forma a personalidade do indivíduo médio e o prepara para viver a cultura: é pela educação que a gênese da cultura se opera no indivíduo. Pode-se descrever a cultura mostrando como o indivíduo a assimila e como nele se constitui, à medida que ele a vai assimilando. Isto porque a educação é, ao mesmo tempo, uma instituição que o indivíduo encontra e o meio que ele tem para encontrar todas as instituições (DUFRENNE, apud BRANDÃO 1986, p.12).

Neste sentido, o PET GAPE realiza suas atividades buscando a participação em escolas e instituições parceiras da comunidade, desenvolvendo seu trabalho em torno das ações e 
práticas pedagógicas e as questões próprias da Educação Popular, baseando-se no diálogo direto com os indivíduos, aprofundando-se dos conhecimentos sobre a sua realidade, efetivando um trabalho de aproximação entre universidade e sociedade.

Devido a específica característica de o grupo ser composto por integrantes de diferentes cursos de graduação, particularidade dos grupos Conexões de Saberes, possibilita que este atue de forma interdisciplinar, contribuindo na troca de saberes na formação acadêmica de seus membros, bem como nos trabalhos que o grupo desenvolve. Consequentemente, este intercâmbio de experiências beneficia tanto o processo de formação dos bolsistas, quanto todos aqueles que estão envolvidos nas atividades do grupo, através de um processo colaborativo.

Diante disso, o presente trabalho foi desenvolvido em parceria com a Escola Municipal de Ensino Fundamental Machado de Assis, localizada no bairro Três Vendas, na cidade de Pelotas/RS, onde o grupo foi construindo gradativamente um relacionamento próximo e profundo, através da participação em projetos, eventos, reuniões, bem como o acompanhamento e colaboração na realização de diversas atividades. Esta aproximação e parceria estão integradas ao projeto de pesquisa do grupo "Educação Popular: um desafio à escola pública". Desta forma, o grupo realiza atividades que têm por objetivo contribuir com o desenvolvimento curricular da escola parceira e o resgate dos saberes de cada sujeito nas atividades próprias a sala de aula.

A Educação Popular, como dito anteriormente, é uma prática pedagógica que valoriza os conhecimentos do povo, trabalhando com base na realidade na qual a comunidade está inserida para a construção de uma escola cidadã e politicamente ativa. Para Vasconcelos (2004, p.71):

Ela busca trabalhar pedagogicamente o homem e os grupos envolvidos no processo de participação popular, fomentando formas coletivas de aprendizado e investigação, de modo a promover o crescimento da capacidade de análise crítica sobre a realidade e o aperfeiçoamento das estratégias de luta e enfrentamento. É uma estratégia de construção da participação popular no redirecionamento da vida social.

Por isso, para o PET GAPE seguir os conceitos nos quais acredita, foi necessária a aproximação com a EMEF Machado de Assis, que possibilitou a realização de um diálogo aberto com a direção da escola, bem como com o corpo docente, onde em uma reunião informal foram apontadas as principais ideias e necessidades da instituição.

A Educação Bancária, segundo Freire, é uma forma de ensino onde os espaços escolares se apresentam estáticos, burocráticos, fixados a um ensino conteudista, de modo que o professor é o centro do processo de aprendizagem e o detentor de conhecimento, e os alunos 
são meros receptáculos dessas informações. A escola parceira, aqui apresentada, sempre se manifestou contrária a esse tipo de educação, criando continuamente materiais didáticos originais e alternativos, construídos coletivamente com seus educandos:

[...] com a utilização de recursos didático-pedagógicos pensa-se em preencher as lacunas que o ensino tradicional geralmente deixa, e com isso, além de expor o conteúdo de uma forma diferenciada, faz os alunos participantes do processo de aprendizagem (CASTOLDI, 2009, p. 685).

Com esse contato mais íntimo com a escola, as professoras apresentaram a dificuldade de se trabalhar com materiais que abordassem a formação histórica da cidade de Pelotas, e a construção dos prédios históricos que abrangem a praça central do município.

Com a modernidade e as novas tecnologias, novos métodos de ensino se mostraram possíveis. A relação que o indivíduo estabelece com o conhecimento, o raciocínio, as informações, a criatividade, agora está em constante transformação, através da chamada cibercultura:

\begin{abstract}
Devemos construir novos modelos do espaço dos conhecimentos. No lugar de representação em escalas lineares e paralelas, em pirâmides estruturadas em 'níveis', organizadas pela noção de pré-requisitos e convergindo para saberes 'superiores', a partir de agora devemos preferir a imagem em espaços de conhecimentos emergentes, abertos, contínuos, em fluxo, não lineares, se reorganizando de acordo com os objetivos ou os contextos, nos quais cada um ocupa posição singular e evolutiva (LÉVY, 1999, p. 158).
\end{abstract}

Em concordância aos pensamentos de Lévy, o crescimento das tecnologias e desse espaço tecnológico possibilitou o desenvolvimento de novas ferramentas de acesso à informação e diferentes modelos de aprendizado, acendendo novas relações com o conhecimento e as possíveis formas de educar. Diante disso, deve-se problematizar a organização do sistema educacional e o papel do educador, que historicamente o construiu como centralizador do conhecimento, e agora, com a facilidade de acesso as informações e a cibercultura, deve passar a ser um incentivador construção coletiva de conhecimento.

Neste sentido, a técnica de animação entra como uma excelente alternativa na construção de materiais originais para a sala de aula. Os desenhos animados estão cada vez mais inseridos no cotidiano das crianças, desta forma, possibilitando sua natural utilização como tática pedagógica, visto que a animação e seus diversos formatos ajudam a transmitir informações de maneira bastante lúdica e marcante para os educandos.

O emprego desse tipo de ferramenta em sala de aula apresenta algumas vantagens, como o fato de prender facilmente a atenção das crianças, além de ter grande efetividade na fixação de conteúdos, porque as informações que por eles são transmitidas são facilmente 
lembradas, por geralmente trabalhar com uma linguagem atrativa para esse tipo de público. Em uma entrevista para o site Escolas Exponenciais, Thelma Oliveira, coordenadora pedagógica da EvoBooks, uma empresa de educação que atua dentro da cultura digital, afirmou:

Ao usar o lúdico, você consegue fomentar aprendizados importantes, trazer questões e novas perspectivas, mas sem perder o encantamento e a curiosidade, permitindo que a criança explore sua imaginação e crie suas próprias expectativas sobre aquilo que está assistindo.

Desta forma, a animação estimula a criatividade e a compreensão das crianças, podendo abordar assuntos complexos ou simples do conteúdo presente no currículo pedagógico, quando estrategicamente trabalhado em conjunto com um exercício, um livro, uma música, ou qualquer outra atividade desenvolvida e mediada pelo professor em sala de aula. Dito isso, é importante ressaltar que o educador deve previamente estar preparado para apresentar esse tipo de conteúdo para que os recursos didáticos alternativos não percam o seu propósito e possam cumprir seu papel no ensino, aproveitando todos os benefícios que os mesmos possam proporcionar. Segundo Silva (2012, p.3):

O professor deve se planejar para que a aplicação desses recursos não se torne meramente uma ação recreativa, eles devem ser usados dentro do processo de ensino-aprendizagem, contribuindo para assimilação do conteúdo ministrado na disciplina, por parte dos alunos.

Com essa perspectiva, EMEF Machado de Assis, bem como o PET GAPE, sempre apresentaram o comum desejo de produzir recursos originais e modernos, desenvolvendo sempre trabalhos bastante criativos. Durante uma das reuniões do grupo com a escola, foi levantada a proposta de se trabalhar o conteúdo sobre o Centro Histórico Pelotense através de um produto audiovisual em animação, que fosse divertido e educativo. Tendo no grupo uma integrante que é graduanda no curso Cinema de Animação na UFPel, qual escreve o presente trabalho, essa ideia foi muito bem acolhida, se iniciando então o processo de realização.

\section{Metodologia}

A partir do próximo contato com a EMEF Machado de Assis, foi desenvolvido um roteiro de estudos sobre os prédios localizados ao redor da praça Coronel Pedro Osório, que fossem relevantes no processo de aprendizado sobre a formação de Pelotas. Os antigos casarões que pertenciam aos barões e membros da elite da região, os prédios governamentais, os centros comerciais, dentre outros prédios marcantes para a cidade, foram considerados. 
Diante disso, foi feito um levantamento dos assuntos que seriam abordados a partir do estudo dessas construções históricas.

Num segundo momento, foi aberto ao diálogo com os educandos do quarto e quinto ano através de uma roda de conversa para fazê-los refletir sobre questões referente aos espaços que os cercam. Foi então mostrado a eles as construções históricas que seriam trabalhadas, onde as educadoras os questionavam em relação a quais daqueles ambientes já eram do seu conhecimento, quais já haviam visitado, o que conheciam sobre a história da formação de Pelotas, se sabiam quando estes prédios foram construídos e qual a sua importância desses prédios para a história da cidade.

A partir das informações coletadas foi possível perceber que mesmo esses lugares estando diariamente presentes em um mesmo espaço geográfico que as crianças, suas histórias muitas vezes eram desconhecidas ou superficialmente conhecidas pelas mesmas. Com isso, foram organizadas aulas dinâmicas através da realização de passeios até esses lugares previamente estudados, onde a visita foi guiada pelos funcionários dos prédios que verdadeiramente dominavam a história e o valor histórico daquele prédio para a formação da cidade de Pelotas;

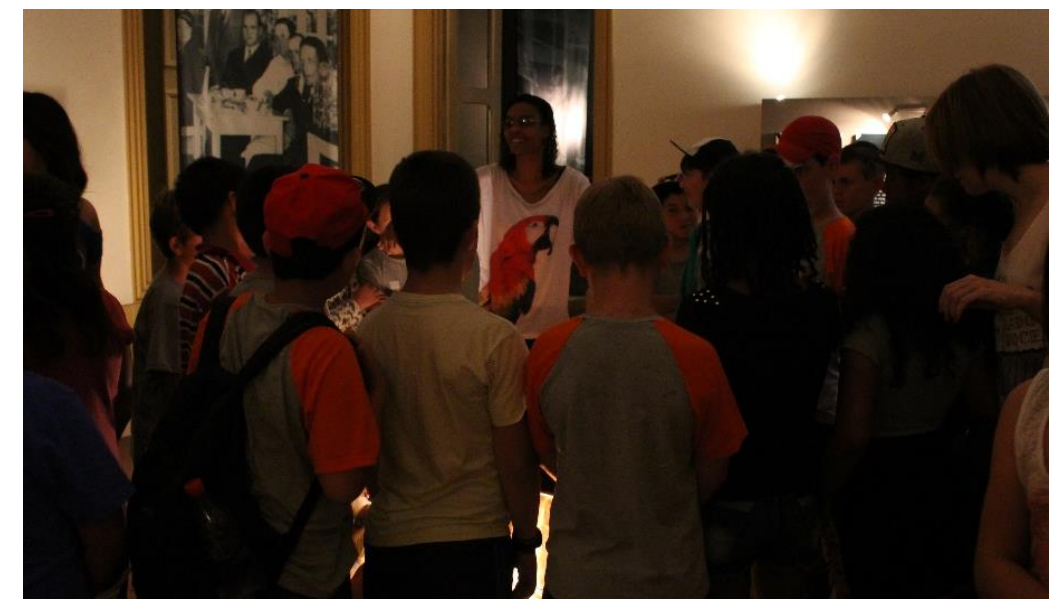

Figura 1 - Visita da EMEF Machado de Assis ao Centro Histórico

Fonte: Acervo do PET GAPE

O PET GAPE acompanhou a escola na realização destas atividades no Centro Histórico Pelotense, e aprendeu muito com a visita, já que muitos dos seus integrantes também não são naturais da cidade. Nesses prédios, localizados principalmente na orla da praça central da cidade, se encontram os principais prédios que esbanjam beleza em seus projetos arquitetônicos e que constituem a história local, nos quais pertenceram a importantes nomes da história brasileira; 

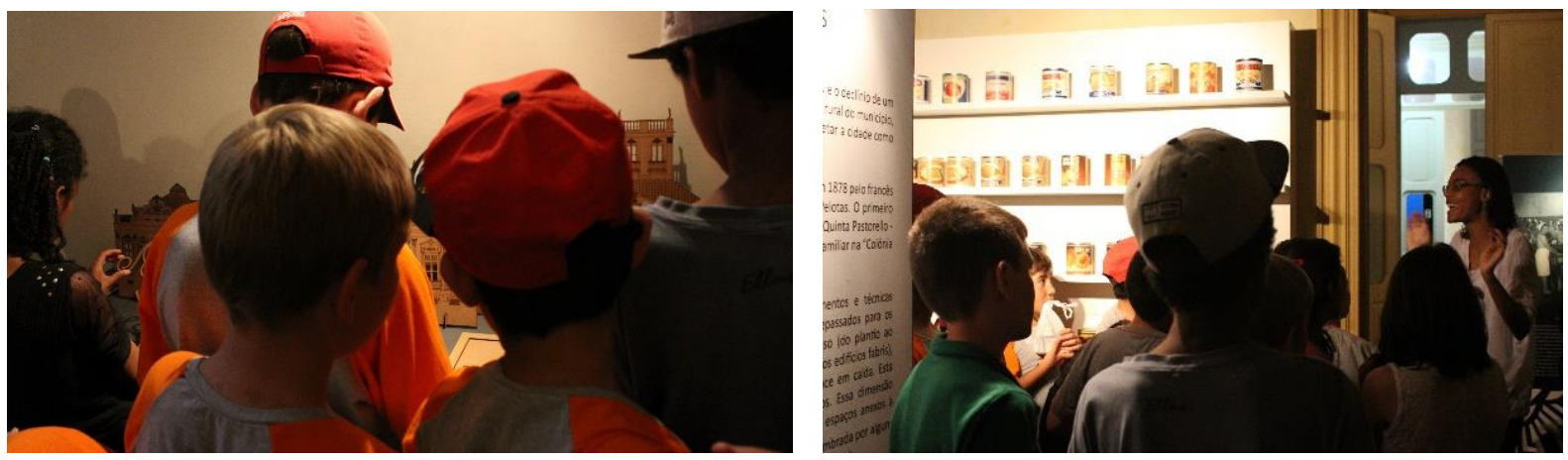

Figuras 2 e 3 - Visita da EMEF Machado de Assis ao Centro Histórico

Fonte: Acervo do PET GAPE

Posteriormente a aula-passeio, retornando à sala de aula, as professora instruíram os educandos a relatar a nova experiência, apontando os momentos mais marcantes da visita, as histórias que mais lhes chamaram a atenção, as construções que eles acharam mais bonitas, e tudo mais que lembravam do passeio, descrevendo suas memórias por meio da escrita ou mediante ilustrações.

Esse foi um momento bastante significante na execução deste trabalho, pois como o grupo atua na perspectiva da educação popular, onde o conhecimento deve ser construído em conjunto, a colaboração dos educandos para a confecção do material didático é de suma importância. Também foram organizadas atividades na escola, para que os educandos pudessem ter elementos para organizarem as informações decorrentes do Projeto Conhecendo Pelotas, onde futuramente seria realizada uma mostra, com os resultados desses aprendizados.

Recolhidos os relatos de experiências dos educandos, as professoras, juntamente a bolsista de Cinema de Animação, planejaram como transmitir esses conteúdos de maneira original, dinâmica e carismática, já que se sustenta uma ação popular. Como afirma Peruzzo: "A comunicação popular foi também denominada de alternativa, participativa, horizontal, comunitária e dialógica, dependendo do lugar social e do tipo de prática em questão." (2006, p. 2). Estava sendo pensado, então, na proposta de se desenvolver uma animação a partir da experiência dos educandos, não apenas para que ficassem registrados esses aprendizados, mas para que estes também contribuam com o currículo escolar, sendo eles apropriados e entendidos de forma divertida, a partir de produções originais.

A animação começou, então, a ser cuidadosamente desenvolvida. Em um primeiro momento, a bolsista precisou se apropriar dos conteúdos selecionados, fazendo uma leitura minuciosa dos materiais desenvolvidos pelos educandos, juntamente com suas professoras. Dado que na Educação Popular não existe apenas uma única fonte detentora de conhecimento, nesse momento já se inicia a troca de saberes entre os indivíduos envolvidos neste processo. 
O aprendizado das crianças foi transferido para a bolsista, instruindo-a não apenas sobre o assunto abordado, mas indiretamente, a mesma passou a conhecer um pouco mais de cada criança, as informações que mais fixaram do passeio, o que era relevante para elas, de modo que cada um dos sujeitos é considerado protagonista dessas histórias.

Feito isso, foi necessário planejar qual seria a melhor maneira de se transmitir as informações recolhidas, para construir um recurso pedagógico que possua, de fato, um diálogo efetivo entre a criança e o conteúdo do material. Optou-se, então, pela apresentação de um personagem carismático, que exibiria através de uma televisão as imagens dos prédios históricos, contando um pouco sobre aquele lugar, a quem pertencia, por que foi criado, qual sua importância atualmente, além de curiosidades relevantes e didaticamente interessantes;

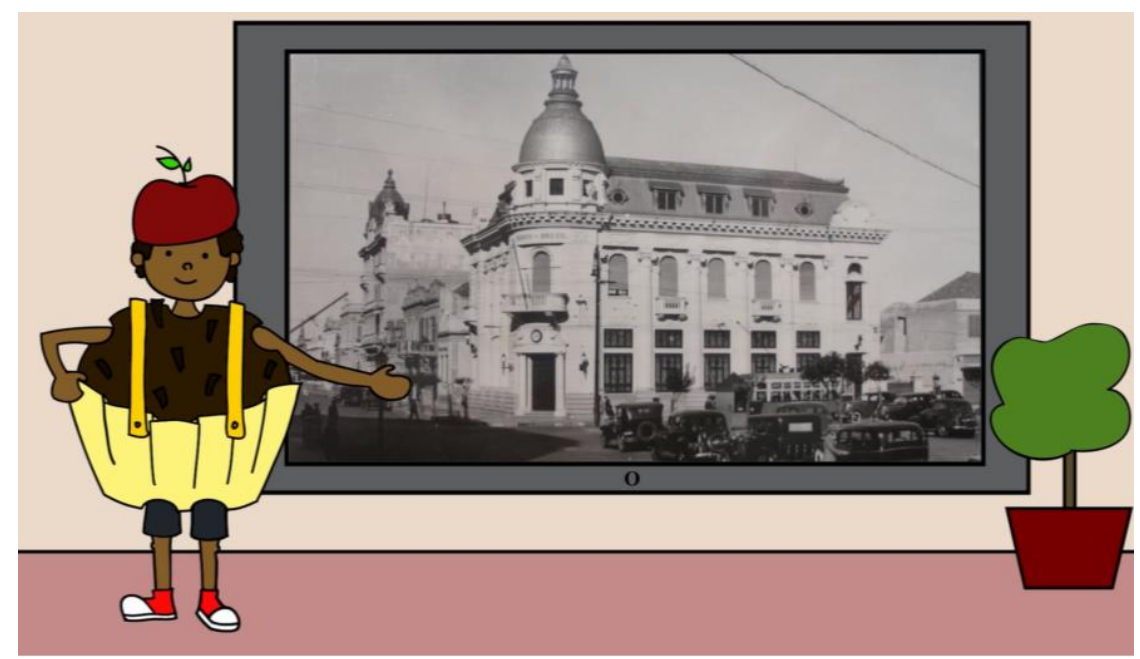

Figuras 4 - Personagem docinho apresentando o conteúdo

Fonte: Captura de tela do vídeo "O Centro Histórico de Pelotas" no YouTube ${ }^{3}$

A partir disso, foi realizado um estudo sobre esse personagem, já que em produtos audiovisuais, a linguagem visual tem enorme relevância. Para um personagem ter apelo e cativar o público, ele essencialmente precisa ter determinados elementos, alguns apresentados por Stephen Silver (2017) como "The Silver Way", qual consiste basicamente em cinco categorias, cada qual com as suas especificidades, para ajudar a construir um personagem sólido e agradável, sendo elas: a história do personagem, seus gestos, o design, suas formas e, por fim, seu detalhamento.

Além do apelo visual, era importante que o personagem também se enquadrasse na realidade vivida pelos educandos da escola que especificamente ajudavam na construção deste

\footnotetext{
${ }^{3}$ Vídeo do canal do PET GAPE no YouTube disponível em: https://www.youtube.com/watch?v=RZe7ZFKNrHM\&t=142s
} 
material, aproximando-se ainda mais destes sujeitos. Por meio do próximo contato com a EMEF Machado de Assis, foi observado que um considerável número de alunos dessa escola são negros, por isso, foi decidido então que o personagem animado também teria tal particularidade, pois representatividade é um fator essencial na atual realidade social, além de promover diversidade nos materiais produzidos pelo grupo, fator extremamente importante qual o programa acredita.

Outra característica importante considerada na construção desse personagem, foi o fato de que a cidade de Pelotas é mundialmente conhecida pelos seus doces, tendo inclusive sua tradição doceira declarada patrimônio imaterial do Brasil em 2018. Com isso em mente, optou-se que o personagem também aderisse essa característica ao seu traje e, então, estaria fantasiado de brigadeiro, regionalmente chamado de negrinho, doce consagrado no país.

Ainda no processo de desenvolvimento, foi feito um estudo de traço, optando-se por um estilo cartunizado, de estética minimalista, já que o produto é destinado para crianças e o cartoon é sempre bem recebido por esse público. Por fim, foi pensado no cenário, na qual se escolheu um estilo simplificado, para não disputar a atenção com o personagem, onde o foco principal deve ser a compreensão do conteúdo qual ele está apresentando.

Já no momento de captação e produção de áudio do produto, foi estudado qual tipo de voz melhor se adequava ao personagem. Fatores como idade, timbre, extensão, linguagem e pronúncia, foram considerados. Com essas características em mente, o graduando de Cinema de Animação, Cesar Boletti, foi convidado a participar do projeto, fazendo assim a voz do menino docinho, qual prontamente aceitou o convite. Foi feito, então, um roteiro qual o dublador deveria seguir, tendo livre autorização para fazer sugestões. Depois disso, a voz foi inserida ao vídeo, onde foi feita a sincronização labial do som com a imagem, para que a boca do personagem se mexesse de maneira minimamente sincronizada a sua voz. Por fim, foi acrescentada também uma música ao fundo, além de alguns efeitos sonoros, para dar mais leveza ao produto.

De modo geral, como resultado, a produção desse material não trouxe aprendizados somente para as crianças as quais o produto se destinava, mas também a todos os bolsistas envolvidos em sua criação. Ademais, a produção de um material original e apropriado, potencializa o anseio da escola de produzir materiais didáticos de forma autônoma e criativa, desejo sempre presente na EMEF Machado de Assis.

É importante ressaltar que, com o projeto finalizado, ele foi exibido em uma mostra de trabalhos realizada para e pela escola, com o tema "Conhecendo Pelotas", onde estiveram presentes os educandos, familiares, professores e funcionários da EMEF. Nessa mostra, foram 
apresentados os trabalhos que seguiam essa temática, desenvolvidos ao longo do ano letivo, sendo eles elaborados pelos alunos, ou projetos parceiros, como a animação sobre o Centro Histórico Pelotense, aqui apresentada, além de um vídeo que apresenta as charqueadas, também desenvolvido pela equipe do PET GAPE em parceria com a escola.

Além disso, a animação foi publicada e compartilhada em todas as plataformas virtuais do grupo, para que esta fique acessível à comunidade em geral, de modo que esse conteúdo possa ser difundido, atingindo ainda mais pessoas, não se limitando apenas aquele ambiente escolar.

\section{Considerações finais}

Através do específico desafio que o PET GAPE tem de atuar seguindo os princípios da Educação Popular, o grupo sempre busca, em seus projetos de pesquisa, ensino e extensão, efetivar a proposta de manter parcerias com escolas públicas, fato que enfatiza a qualidade alcançada em seus projetos, tornando as experiências e resultados mais enriquecedores, qual possibilitou surgir a necessidade do presente trabalho.

Diante da perceptível realidade, onde muitas escolas ainda apresentam dificuldades em se desvincular do padrão de ensino arcaico e conteudista, surgiu a proposta de se trabalhar com recursos didáticos originais e alternativos, construção coletiva de extrema importância que reafirma a importância desse trabalho.

A partir da necessidade desses materiais, notou-se a possibilidade de se trabalhar com a animação em sala de aula, de modo que ela não se mostrou apenas como uma alternativa de ferramenta pedagógica, mas apresentou principalmente resultados muito positivos durante a sua execução.

De modo geral, todas as etapas de desenvolvimento deste trabalho colaboraram na formação acadêmica e cidadã dos bolsistas, dando a eles a oportunidade de colocar em prática os aprendizados adquiridos ao longo da graduação, podendo atuar em suas áreas de formação, com o objetivo de adquirir um resultado coletivo. Além disso, diante da profunda pesquisa sobre o Centro Histórico Pelotense, os bolsistas puderam também se aproximar ainda mais da cultura e tradição local, fortalecendo o sentimento de pertencimento e zelo pelos espaços.

Por meio da parceria e do próximo contato que a EMEF Machado de Assis e o PET GAPE construíram, foi possível desenvolver um produto autêntico e diferenciado que suprisse uma específica demanda escolar. Este fato reafirma a importância do diálogo entre a universidade e a comunidade, onde o respeito e a colaboração sejam mútuos, promovendo 
intercâmbio de conhecimentos e proporcionando aos educandos uma maneira prazerosa e lúdica de aprender, principal objetivo almejado desde a idealização do projeto.

\section{Referências}

BRANDÃO, C. R. Educação popular. São Paulo: Editora Brasiliense, 1986. Disponível em: http://www.acervo.paulofreire.org:8080/jspui/bitstream/7891/4211/1/FPF_PTPF_01_0864.pd f. Acesso em: 07 jan. 2019.

CASTOLDI, R.; POLINARSKI, C. A. A utilização de recursos didático-pedagógicos na motivação da aprendizagem. I Simpósio Nacional de Ensino de Ciências e Tecnologia, 1. 2009, Paraná. Anais... Paraná: UTFPR, p. 684-692, 2009. Disponível em: https://atividadeparaeducacaoespecial.com/wp-content/uploads/2014/09/recursos-didaticopedag\%C3\%B3gicos.pdf. Acesso em: 08 jan. 2019.

Escolas Exponenciais. Como os desenhos animados podem ajudar no desenvolvimento das crianças? Disponível em: https://escolasexponenciais.com.br/como-os-desenhos-animadospodem-ajudar-no-desenvolvimento-das-criancas/. Acesso em 12 jan. 2019.

LÉVY, P. Cibercultura. São Paulo: Editora 34, 1999. Disponível em: https://mundonativodigital.files.wordpress.com/2016/03/cibercultura-pierre-levy.pdf. Acesso em: 11 jan. 2019.

PERUZZO, Z. M. K. Revisitando os Conceitos de Comunicação Popular, Alternativa e Comunitária. In: CONGRESSO BRASILEIRO DE CIÊNCIAS DA COMUNICAÇÃO, 29., 2006, Brasília. Disponível em: http://www.portcom.intercom.org.br/pdfs/116338396152295824641433175392174965949.pd f. Acesso em: 07 jan. 2019.

SILVA, M. A. S. et al. Utilização de Recursos Didáticos no processo de ensino e aprendizagem de Ciências Naturais em turmas de $8^{\circ}$ e $9^{\circ}$ anos de uma Escola Pública de Teresina no Piauí. In: CONNEPI-Congresso Norte Nordeste de Pesquisa e Inovação, 7., 2012, Tocantins. Disponível em: http://propi.ifto.edu.br/ocs/index.php/connepi/vii/paper/viewFile/3849/2734. Acesso em: 10 jan. 2019.

SILVER, S. The Silver Way: Techniques, tips and tutorials for effective character design. China: Design Studio Press, 2017.

VASCONCELOS, E. M. Educação popular: de uma prática alternativa a uma estratégia de gestão participativa das políticas de saúde. Physis: revista de saúde coletiva, v. 14, p. 67-83, 2004. Disponível em: http://www.scielo.br/pdf/\%0D/physis/v14n1/v14n1a05.pdf. Acesso em: 10 jan. 2019. 